\title{
PRÁTICAS DE ENFERMAGEM EMPREENDEDORAS E AUTÔNOMAS
}

\author{
Joice Aparecida de Morais ${ }^{1}$, Maria do Carmo Lourenço Haddad², Mariana Angela Rossaneis ${ }^{3}$
} Larissa Gutierrez de Carvalho da Silva ${ }^{4}$

\begin{abstract}
RESUMO: Estudo descritivo, com abordagem quantitativa, teve como objetivo caracterizar as práticas de enfermagem empreendedoras no Estado do Paraná. Foi realizada uma amostra intencional por convite a 11 enfermeiros com empreendimentos na área da saúde, os dados foram coletados por meio de questionário online. Os resultados apontam uma população adulta jovem; com prevalência feminina e experiências profissionais variadas. O interesse pelo empreendedorismo surgiu da busca pela satisfação profissional; a gestão de negócios foi destacada como habilidade necessária para empreender. Em relação às facilidades e dificuldades para abrir o próprio negócio, destaca-se o apoio de outros profissionais e as questões burocráticas; os participantes mostraram-se satisfeitos com seus empreendimentos. Conclui-se que a enfermagem tem caminhado e explorado um novo mercado, promovendo a profissão como capaz de conduzir sua prática de forma autônoma e inovadora. DESCRITORES: Autonomia profissional; Serviços de enfermagem; Mercado de trabalho; Empresas e organizações de serviço.
\end{abstract}

\section{AUTONOMOUS AND BUSINESS PRACTICES IN NURSING}

\begin{abstract}
This descriptive study with a quantitative approach aimed to characterize the business practices in nursing in the state of Paraná. An intentional sample was undertaken by invitation to 11 nurses with businesses in the health area, the data collected via an online questionnaire. The results point to a young adult population; with a predominance of females and with varying professional experience. The interest in entrepreneurship arose from the search for professional satisfaction; business management was emphasized as the skill necessary to run a business. In relation to the easy aspects and difficulties for opening one's own business, support from other professionals and bureaucratic issues stand out; the participants showed themselves to be satisfied with their businesses. It is concluded that nursing has sought and explored a new market, promoting the profession as able to conduct its practice autonomously and innovatively. DESCRIPTORS: Professional autonomy; Nursing services; Job market; Companies and service organizations.
\end{abstract}

\section{PRÁCTICAS DE ENFERMERÍA EMPRENDEDORAS Y AUTÓNOMAS}

RESUMEN: Estudio descriptivo, con abordaje cuantitativo que tuvo el objetivo de caracterizar las prácticas de enfermería emprendedoras en Estado de Paraná. Fue realizada una muestra intencional por invitación a 11 enfermeros con emprendimientos en área de salud. Los datos fueron recogidos por medio de cuestionario online. Los resultados apuntan una población adulta joven; con prevalencia femenina y experiencias profesionales variadas. El interés por el hecho de emprender surgió de la búsqueda por la satisfacción profesional; la gestión de negocios fue destacada como habilidad necesaria para emprender. Acerca de las facilidades y dificultades para abrir el propio negocio, se destaca el apoyo de otros profesionales y las cuestiones burocráticas; los participantes se mostraron satisfechos con sus emprendimientos. Se concluye que la enfermería viene caminando y explorando un nuevo mercado, promoviendo la profesión como capaz de conducir su práctica de forma autónoma e innovadora.

DESCRIPTORES: Autonomía profesional; Servicios de enfermería; Mercado de trabajo; Empresas y organizaciones de servicio.

\footnotetext{
${ }^{1}$ Enfermeira. Residente em Gerência de Serviços de Enfermagem do Hospital Universitário da Universidade Estadual de Londrina - UEL. ${ }^{2}$ Enfermeira. Doutora em Enfermagem. Professora do Departamento de Enfermagem da UEL. Coordenadora da Residência em Gerência de Serviços de Enfermagem da UEL.

${ }^{3}$ Enfermeira. Mestre em Ciências. Doutoranda pelo Programa de Pós-Graduação em Enfermagem da Universidade Estadual de Maringá. Professora do Departamento de Enfermagem da UEL.

${ }^{4}$ Enfermeira. Mestre em Enfermagem. Doutoranda pelo Programa de Pós-Graduação da Escola de Enfermagem de Ribeirão Preto da Universidade de São Paulo.
} 


\section{INTRODUÇÃO}

Nas últimas décadas, muito se tem discutido sobre as transformações econômicas, inovações tecnológicas e a globalização ${ }^{(1)}$. Nessa nova Era, as transformações acabam por causar impactos no mercado de trabalho, resultando em aumento da taxa de desemprego, redução de salários e mercados cada vez mais competitivos ${ }^{(2)}$.

Diferente dos objetivos profissionais dos trabalhadores do mundo industrial, onde a busca era por estabilidade no mercado de trabalho, o novo modelo econômico emerge de profissionais com propósitos diferentes, destacando nesse cenário o empreendedorismo como forma de se chegar à satisfação no trabalho e alcançar a autonomia profissional ${ }^{(1)}$. Empreendedorismo é definido como a criação ou aperfeiçoamento de algo, que nenhum outro viu, com a finalidade de gerar benefícios aos indivíduos e à sociedade ${ }^{(3)}$. Uma das definições mais remotas para empreendedor é a do economista Josh Schumpeter, na qual empreendedor é aquele que produz, aprimora ou reorganiza processos, recursos e ou materiais diferentes dos habituais ${ }^{(4)}$. No Brasil, a atividade ganhou destaque a partir da década de 1990, com o aumento das políticas de estimulação à abertura de micro e pequenas empresas; o empreendedorismo surgiu, naquele momento, vislumbrando a capitalização sobre o seu próprio negócio(5).

$\mathrm{Na}$ área da saúde, o empreendedorismo tem se destacado em função da necessidade de gerar novos postos de trabalho. O número crescente de cursos de enfermagem no Brasil, com destaque nas instituições privadas, gera por ano elevado contingente de ingressantes no mercado de trabalho, o que evidencia a necessidade de alternativas de atuação de forma autônoma ${ }^{(6)}$. Neste sentido, o enfermeiro empreendedor possui a capacidade de cuidar holisticamente, independentemente das condições sociais, políticas ou econômicas ${ }^{(7)}$.

De acordo com o parecer ministerial de outubro de 1946, o enfermeiro é reconhecido como profissional liberal e tem a liberdade do exercício autônomo ${ }^{(8)}$, autonomia esta posta em prática nas intervenções próprias da profissão e realizadas por meio do planejamento, organização, coordenação, execução e avaliação dos serviços e da assistência de enfermagem oferecida aos clientes, independentemente do local de atuação( ${ }^{(9)}$.

O estímulo ao empreendedorismo autônomo do enfermeiro é de inestimável relevância por possibilitar a conquista de novos campos de atuação voltados ao cuidado do cliente/paciente, por agregar valor à profis- são frente à sociedade, e por impulsionar o crescimento econômico de um país, uma vez que as empresas formadas geram empregos a uma parcela da população.

A pesquisa justifica-se pela necessidade de promover a Enfermagem como profissão empreendedora e capaz de conduzir sua prática de forma autônoma e inovadora. Sendo assim, este estudo teve por objetivo caracterizar as práticas de enfermagem empreendedoras e autônomas.

\section{MÉTODO}

Trata-se de uma pesquisa descritiva, com abordagem quantitativa, realizada no período de setembro a dezembro de 2012, que teve como população do estudo enfermeiros legalmente habilitados que exerciam atividades empreendedoras e de forma independente no Estado do Paraná, há pelo menos um ano.

Foram solicitados, a dois informantes-chave que exerciam atividade empreendedora no Estado, os contatos dos enfermeiros que possuíam seu próprio negócio na área da saúde e que trabalhavam de forma autônoma. A partir dessa identificação foi realizada uma amostra intencional por convite aos enfermeiros que se enquadraram nos critérios de inclusão, sendo esses: ser enfermeiro; ter seu próprio negócio na área da saúde; estar com a empresa ativa no Estado do Paraná, e concordar em participar da pesquisa, após o convite por contato telefônico. Entre 14 enfermeiros empreendedores 11 aceitaram participar da pesquisa.

Os dados foram coletados por meio de questionário online elaborado no programa Google Docs ${ }^{\circledR}$ que possuía questões referentes à caracterização da população: sexo, idade ao abrir seu próprio negócio, formação profissional, experiência profissional anterior, e tempo de experiência antes de abrir seu próprio negócio. $\mathrm{O}$ questionário incluía também a caracterização da empresa, com as atividades oferecidas e renda mensal; e questões referentes às perspectivas ao abrir o próprio negócio, facilidades e dificuldades encontradas e grau de (in) satisfação com o negócio.

Os questionários foram enviados aos enfermeiros por correio eletrônico e os dados foram transferidos para o programa Microsoft Excel $2010 \AA$, e procedeu-se a análise estatística simples dos resultados.

O projeto de pesquisa foi aprovado pelo Comitê de Ética em pesquisa da UEL, cadastrado no Sistema Nacional de Informação sobre Ética em Pesquisa com CAAE n. 07301912.0.0000.5231. 


\section{RESULTADOS}

Os empreendimentos identificados foram: instituição de moradia temporária e permanente para idosos (04); clínica de assistência domiciliar (03); consultoria e atendimento de enfermagem em áreas especializadas (02); assessoria (01) e serviços que oferecem treinamentos, cursos preparatórios e de aperfeiçoamento a profissionais (01).

O perfil analisado dos profissionais enfermeiros encontra-se descrito na tabela 1.

Tabela 1 - Características profissionais de enfermeiros empreendedores. Paraná, 2012

\begin{tabular}{lcc}
\hline Característica Profissional & N & \% \\
\hline Sexo & & \\
Feminino & 10 & 91 \\
Masculino & 01 & 09 \\
Idade ao abrir seu próprio negócio & & \\
20 a 29 anos & 02 & 18 \\
30 a 39 anos & 05 & 45 \\
40 a 49 anos & 04 & 37 \\
Acima de 50 anos & - & - \\
Experiência profissional anterior (anos)* & \\
Área Hospitalar & 11 & 100 \\
Área de Ensino & 09 & 82 \\
Atenção básica & 06 & 54 \\
Outras áreas & 02 & 18 \\
Tempo de experiência profissional antes de abrir \\
seu próprio negócio* & \\
1 a 2 anos & 02 & 18 \\
3 a 10 anos & 03 & 27 \\
11 a 15 anos & 03 & 27 \\
16 a 20 anos & 03 & 27 \\
\hline
\end{tabular}

* Algumas questões permitiam mais do que uma resposta.

Foi possível verificar nos resultados da pesquisa que todos empreendedores foram motivados pela oportunidade nos negócios. O despertar do interesse em abrir seu próprio negócio para sete participantes surgiu a partir da busca pela satisfação profissional, exercendo uma prática diferenciada com o paciente e a família; em seguida $(\mathrm{n}=5)$ a constatação da necessidade no mercado da atividade que desenvolve; a independência financeira foi relatada por três, ressaltando nas informações os baixos salários oferecidos à categoria nos serviços privados. O desgaste emocional por trabalhar muito tempo como empregado foi relatada por um enfermeiro como fator motivador do desejo de gerenciar algum bem e ser seu próprio patrão.

Quanto às habilidades e conhecimentos necessários para se tornar empreendedor, a gestão de negócios ganhou destaque ao ser referida por nove pesquisados. A disciplina, organização e inovação, foram citadas por quatro enfermeiros; seguida da habilidade de comunicação, criatividade e marketing $(\mathrm{n}=3)$; o autocontrole, prazer pelo que pretende desenvolver e coragem para assumir e enfrentar os riscos foram citados por dois empreendedores. Quando essas habilidades são ainda pouco desenvolvidas, a assessoria de um profissional capacitado na área do empreendedorismo também foi mencionada como estratégia facilitadora para a abertura e sucesso do negócio.

Os entrevistados foram questionados também quanto às facilidades e dificuldades para abrir seu próprio negócio; destaca-se o apoio de outros profissionais da área da saúde $(\mathrm{n}=6)$; conhecimento em administração hospitalar (n=3); e importância de possuírem um capital inicial para investimento $(\mathrm{n}=2)$. As dificuldades apresentadas foram burocracias com alvarás, licenças e credenciamentos $(\mathrm{n}=7)$; inexperiência no ramo do empreendedorismo, dificuldade na seleção de pessoal para contratação e na divulgação da empresa $(n=2)$; apenas um enfermeiro citou a falta de recursos financeiros.

Quanto à renda mensal, seis empreendedores se enquadraram na faixa de quatro a dez salários mínimos, seguidos de três entre dois e quatro salários e com uma discrepância significante, encontramos um empreendedor com rendimento inferior a dois salários mínimos e outro acima de 20 salários mínimos. Relativo ao grau de (in) satisfação profissional enquanto empreendedor, a maioria $(n=6)$ se declarou satisfeito, quatro afirmaram estar muito satisfeitos e um pouco satisfeito.

Ao serem questionados sobre as expectativas em relação ao futuro, verificou-se que todos tinham perspectivas de expansão e crescimento nos negócios e nenhum manifestou interesse em desistir do empreendimento.

\section{DISCUSSÃO}

O estudo evidencia que o enfermeiro possui campo de atuação para o empreendedorismo, indo ao encontro da afirmativa de que o profissional empreendedor tem a possibilidade de disponibilizar serviços de enfermagem envolvendo a prestação de cuidados, educação, pesquisa, administração ou consultoria ${ }^{(10)}$. O empreendedorismo na enfermagem é favorecido por três razões: a perspectiva de prestar assistência holística desenvolvida no curso de graduação; os diferenciados campos de atuação profissional existentes para 
prestação de serviços, e como terceiro, e não menos importante, o gênero feminino, que tem adquirido espaço no empreendedorismo ${ }^{(11)}$.

Os resultados do estudo coincidem com o perfil analisado dos profissionais enfermeiros. Identificou-se que a maior parte dos participantes era do sexo feminino $(\mathrm{n}=10)$. A participação da mulher no mercado de trabalho cresce significativamente em todo mundo. Em 2010 as brasileiras ganharam destaque nesse cenário, por representarem metade dos empreendedores brasileiros $(49,3 \%)^{(12)}$.

A população ao iniciar seu próprio negócio é caracterizada também por pertencer a uma faixa etária adulta jovem, com o maior número de profissionais entre 30 e 39 anos, coincidindo assim, com o perfil dos empreendedores brasileiros em fase inicial. Isso comprova que o empreendedorismo tem sido cada vez mais visto como uma opção de carreira para os novos profissionais no mercado de trabalho ${ }^{(13)}$. O perfil do jovem criativo, ousado e determinado, associado ao incentivo por meio de projetos voltados a capacitação empreendedora ajuda a difundir a cultura de ser dono do seu próprio negócio ${ }^{(14)}$.

As experiências profissionais adquiridas, o desenvolvimento técnico e a maturidade profissional conquistada durante os anos de trabalho, também são facilitadores da visualização e desenvolvimento de oportunidades $^{(15)}$. A população de estudo, ao se tornar empreendedor, possuía média de 10 anos de experiência profissional. Durante esse tempo, essas experiências se deram nas variadas áreas de atuação, com destaque no âmbito hospitalar, contemplando todos participantes. Além desses aspectos facilitadores, o preparo administrativo é fundamental para tornar a empresa bem sucedida. Dados do Serviço Brasileiro de Apoio às Micro e Pequenas Empresas demonstram que a taxa de mortalidade das empresas vai de $29 \%$ no primeiro ano, chegando a $56 \%$ nos primeiros cinco anos, sendo a principal causa o comportamento empreendedor pouco desenvolvido e deficiente antes da abertura do negócio ${ }^{(16)}$.

Para compreender o porquê optar pelo empreendedorismo, encontramos na literatura, dois fatores motivacionais para iniciar um negócio, sendo esses a oportunidade, que ocorre quando o indivíduo opta pelo empreendedorismo ao identificar uma oportunidade de negócio; ou a necessidade, ou seja, pela falta de opções ou insatisfação no mercado. Estudos demonstram um aumento no número de empreendedores por oportunidade, como constatado também nos resultados dessa pesquisa, o que evidencia a abertura do mercado a no- vos empreendimentos, além da capacidade do empreendedor de identificar novas oportunidades de trabalho ${ }^{(17)}$.

Unido à oportunidade visualizada pelo profissional, a troca da estabilidade do emprego tradicional por assumir os riscos de empreender seu próprio negócio, é o reflexo da mudança no comportamento e nos valores profissionais pelo desejo de sair da rotina e de buscar novos desafios ${ }^{(1)}$. Outro desejo relatado por $64 \%$ dos pesquisados está relacionada à busca pela satisfação profissional. Estudo realizado na China em 2008, país com elevado potencial inovador, demonstra que as mudanças políticas, culturais e psicológicas, como a legitimidade do empreendedorismo, contribuem para a mudança do perfil de trabalho, ganhando espaço assim o empreendedorismo ${ }^{(18)}$.

A iniciativa de abrir um negócio próprio exige, porém habilidades do profissional empreendedor. Falta de preparo, planejamento e conhecimento específico sobre o negócio que se pretende dar início é uma das maiores dificuldades dos novos empreendedores. Além dessas habilidades, empreendedores são pessoas visionárias em relação ao futuro nos negócios; possuem facilidades e agilidade nas tomadas de decisões; são profissionais com visão diferenciada na identificação de oportunidades, dedicados, determinados, dinâmicos, organizados dentre outros atributos que diferenciam esses profissionais no mercado de trabalho ${ }^{(19)}$.

Frente a essa questão, a habilidade na gestão do negócio foi mencionada pela maioria $(82 \%)$, ressaltando o conhecimento financeiro, administrativo, de mercado, gerenciamento de recursos humanos e informática. A administração das micro e pequenas empresas bem sucedidas são aquelas que, ao iniciarem, levaram em conta a presença de um profissional capacitado à frente dos negócios, o conhecimento do mercado onde iriam atuar e o investimento financeiro próprio ${ }^{(20)}$.

O trabalho nesse ramo é árduo e competitivo, marcado por dedicação e muitas horas de trabalho diário( ${ }^{(1)}$. $\mathrm{O}$ apoio de outros profissionais, tanto empreendedores como colegas de trabalho, auxiliando na divulgação e no encaminhamento de clientes, se destaca em 54,5\% dos pesquisados como facilitador para o empreendedorismo. Algumas características contribuem para o crescimento e sucesso dos negócios, tais como visão estratégica, inovação, zelo no atendimento aos clientes, profissionalismo e seriedade ${ }^{(21)}$. O desejo de trabalhar em um ambiente desafiador, com possibilidade de realização pessoal, e oportunidade de usufruir da criatividade, são condições motivadoras e, portanto, facilitadores para tornar-se empreendedor ${ }^{(1)}$. 
Dificuldades também foram relatas ao abrir seu próprio negócio. Em aproximadamente $64 \%$ dos pesquisados a questão burocrática ganhou destaque. Outra dificuldade, como a inexperiência no ramo do empreendedorismo, foi relada nessa questão por $18 \%$ dos pesquisados. Porém, ao responderem outras questões, a falta de experiência esteve sempre presente nas falas como fator dificultador do processo. A insuficiência na preparação acadêmica para o desenvolvimento das habilidades empreendedoras dos estudantes, aliada a cultura do serviço assalariado tradicional e o pouco incentivo de programas de apoio ao empreendedorismo é encontrada também na literatura ${ }^{(22)}$.

Mesmo com todo preparo e habilidades, o sucesso da empresa pode não atender as perspectivas do empreendedor precocemente. Para iniciar um negócio, além do investimento necessário, é importante considerar que o retorno financeiro pode tardar a surgir. No que se refere aos rendimentos em salários mínimos no valor de R $\$ 622,00$ em $2012^{(23)}, 54,5 \%$ se encontravam dentro da renda de quatro a 10 salários mínimos; grande discrepância entre a renda de dois dos pesquisados foi também observada. Um fator que talvez explique essa diferença entre os extremos de dois dos pesquisados é por um lado, um profissional que se encontra no início de sua carreira empreendedora, portanto dentro de uma faixa salarial inferior, e por outro lado, um empreendedor com perfil inovador e único na cidade onde se encontra a empresa, ganhando destaque no que se refere ao rendimento. A dificuldade relacionada à questão financeira é também mencionada na literatura ${ }^{(24)}$.

Frente às facilidades e, principalmente, dificuldades que sabiamente seriam encontradas na pesquisa, conhecer o nível de satisfação e insatisfação dos pesquisados foi importante. Como verificado nos resultados, encontramos a prevalência de uma população entre muito satisfeita $(54,5 \%)$ e satisfeita $(36,3 \%)$ com seu negócio. A satisfação alcançada pelas expectativas, os desejos e as necessitadas atendidas contribuem para o bom relacionamento no ambiente de trabalho, no serviço oferecido pela empresa e no anseio em fazer seu negócio alcançar sucesso( ${ }^{(25)}$.

Em relação às perspectivas futuras, a pesquisa mostrou uma população com futuro promissor nos negócios. A visibilidade do trabalho do enfermeiro nos variados locais de atuação vem se expandindo; porém é fundamental que esta assuma cada vez mais novos desafios, superando, ultrapassando e avançando para uma prática capaz de atuar com autonomia e atitudes empreendedoras ${ }^{(26)}$.

\section{CONSIDERAÇÕES FINAIS}

O estudo com enfermeiros empreendedores ressalta o empreendedorismo como oportunidade do enfermeiro alcançar a satisfação profissional. Embora os resultados evidenciassem as dificuldades encontradas no processo de empreender, principalmente quanto a identificação e aquisição de conhecimento sobre as atividades de prestação de serviços que se pretende iniciar, no planejamento e na organização da atividade a ser implementada, conhecer as estratégias que outros enfermeiros empreendedores adotaram, possibilita que os enfermeiros empreendedores avaliem os riscos de seu novo negócio e se preparem adequadamente.

A enfermagem tem caminhado e explorado um novo mercado de trabalho. O desafio apresenta riscos, mas também benefícios e oportunidades de exercer trabalho autônomo e inovador à população. A profissão tem adquirido maior visibilidade, espaço e reconhecimento, capaz de partir de sua posição subordinada e voltada às atividades técnicas, para um profissional que vem ganhando espaço ao assumir a gestão de serviços de saúde, com seu potencial autônomo, especialista, e empreendedor.

Tornar-se empreendedor, seja pela necessidade, pela ausência de boas alternativas ou pelo desejo inovador, é um trabalho árduo, onde mesmo com os possíveis riscos a satisfação se mostra presente. Porém, para se tornar um empreendedor bem sucedido é preciso se preparar administrativa e financeiramente, saber onde se deseja chegar, fazer as escolhas corretas e inovar sempre.

Para o desenvolvimento do estudo, foram encontradas algumas limitações referentes à identificação dos participantes e a obtenção das respostas do questionário dentro do prazo determinado. No entanto, a pesquisa contribui para ampliação dos campos disponíveis de empregos aos profissionais enfermeiros e permite avanços na profissão ao direcionar a prática de atuação a novas possibilidades.

\section{REFERÊNCIAS}

1. Guimarães SMK, Azambuja LR. Empreendedorismo high-tech no Brasil: condicionantes econômicos, políticos e culturais. Soc.estado.[Internet] 2010;25(1) [acesso em 17 jan 2013]. Disponível: http://dx.doi. org/10.1590/S0102-69922010000100006

2. Costa MTG, Carvalho LC. A educação para o empreendedorismo como facilitador da inclusão social: um caso no ensino superior. Rev. Lusófona de Educação. [Internet] 2011;(19) [acesso em 17 jan 2013]. Disponível: 
http://www.scielo.gpeari.mctes.pt/scielo.php?pid=S164 $572502011000300007 \&$ script $=$ sci_arttext.

3. Fiorin MMB, Mello CM, Machado HV. Empreendedorismo e inovação: análise dos índices de inovação dos empreendimentos brasileiros com base nos relatórios do GEM de 2006, 2007 e 2008. Rev. Adm. UFSM. [Internet] 2010;3(3) [acesso em 18 jan 2013]. Disponível: http://cascavel.ufsm.br/revistas/ojs-2.2.2/ index.php/reaufsm/article/view/1583/1525.

4. Schumpeter JA. Teoria do Desenvolvimento Econômico: uma investigação sobre lucros, capital, crédito, juro e ciclo econômico. Rio de Janeiro: Editora Fundo de Cultura; 1961.

5. Zouain DM, Barone FM. Empreendedorismo feminino no Brasil: políticas públicas sob análise. Rev. Adm. Pública. [Internet] 2009;43(1) [acesso em 21 jan 2013]. Disponível: http://dx.doi.org/10.1590/S003476122009000100011

6. Teixeira E,Vale EG, Fernandes JD, De Sordi MRL. Trajetória e tendências dos Cursos de Enfermagem no Brasil. Rev. bras. enferm. [Internet] 2006;59(4)[acesso em 21 jan 2013]. Disponível: http://dx.doi.org/10.1590/ S0034-71672006000400002

7. Roncon PF, Munhoz S. Estudantes de enfermagem têm perfil empreendedor? Rev. bras. enferm. [Internet] 2009;5(62) [acesso em 21 jan 2013].Disponível: http:// dx.doi.org/10.1590/S0034-71672009000500007

8. Santos EF, Santos EB, Santana GO, Assis MF, Oliveira R. Legislação em enfermagem. São Paulo:Atheneu; 2006.

9. Bais DDH. Política nacional de atenção básica à saúde, formação acadêmica e atuação profissional do enfermeiro: aproximações e distanciamentos [tese]. Curitiba (PR): Universidade Federal do Paraná; 2009.

10. International Council Of Nurses.Guidelines on the nurse entre/intrapreneur providing nursing service.Geneva; 2004 [acesso em 21 jan 2013].Disponível: http:// www.crnns.ca/documents/Self\%20Emp\%20Practice/ Guidelines\%20for\%20Nurse\%20Entrepreneurs\%20 (ICN).pdf.

11. Leong SL. Clinical nurse specialist entrepreneurship. The Internet Journal of Advanced Nursing Practice [Internet] 2005;7(1) [acesso em $15 \mathrm{mar} 2013$ ]. Disponível: http://archive.ispub.com/journal/theinternet-journal-of-advanced-nursing-practice/volume7-number-1/clinical-nurse-specialist-entrepreneurship. html\#sthash.3RrBQUVM.dpuf. doi: 10.5580/277a.
12. Greco SMSS, Fried-laender J, Romeu H, Duarte ECVG, Rissete CR, Felix JC, et al. Empreendedorismo no Brasil: Curitiba; 2010. IBQP. 286 p.

13. Greco SMSS, Duarte ECVG, Sarfati G, Rissete CR, Felix JC, Machado JP, et al. Empreendedorismo no Brasil Brasil: Curitiba; 2011. IBQP. 118p.

14. Portal Brasil [Internet]. Jovens Empreendedores [acesso em 15 mar 2013]. Disponível: http://www.brasil.gov. br/empreendedor/empreendedorismo-hoje/jovensempreendedores.

15. Degen RJ. Empreendedorismo: uma filosofia para o desenvolvimento Sustentável e a redução da pobreza. Rev. Ciênc. Adm. [Internet] 2008;10(21) [acesso em 17 jan 2013]. Disponível: http://www.periodicos.ufsc.br/ index.php/adm/article/view/2175-8069.2008v10n21p11. doi: $10.5007 / 2175-8069.2008 v 10 \mathrm{n} 21 \mathrm{p} 11$.

16. Serviço Brasileiro de Apoio às Micro e Pequenas Empresas (SEBRAE). Sobrevivência e Mortalidade das Empresas Paulistas de 1 a 5 anos. São Paulo: SEBRAE; 2007. 25 p. Relatório final.

17. Damasceno LDJ. Empreendedorismo Feminino: um estudo das mulheres empreendedoras com modelo proposto por Dornelas [monografia]. Fortaleza (CE): Faculdade 7 de setembro; 2010.

18. Eesley CE. "Who jumps into the sea and when? Entrepreneurship and policy change in China". [Paper presented at the SASE Congress, electronic copy]; 2008.

19. Dornelas JCA. Empreendedorismo: transformando idéias em negócios. 3a ed. Rio de Janeiro: Elsevier; 2008. $2^{\mathrm{a}}$ reimpressão.

20. Tachizawa T, Pozo H.Gestão de recursos humanos em micro e pequenas empresas: um enfoque de gestão ambiental e responsabilidade social para seu crescimento.Revista da Micro e Pequena Empresa [Internet] 2007;1(1)[acesso em 23 mar 2013]. Disponível: http://www.faccamp.br/ojs/index.php/ RMPE/article/view/13.

21. Chiavenato I. Empreendedorismo: Dando asas ao espírito empreendedor. $2^{\mathrm{a}}$ ed. São Paulo: Saraiva; 2007.

22. Araújo MH, Lago RM, Oliveira LCA, Cabral PRM, Cheng LC, Filion LJ. O estímulo ao empreendedorismo nos cursos de química: formando químicos empreendedores. Quim. Nova. [Internet] 2005;28 [acesso em 26 mar 2013]. Disponível: http://dx.doi. org/10.1590/S0100-40422005000700005 
23. Ministério da Saúde (BR). Decreto n. 12.382, de 25 de fevereiro de 2011: Dispõe sobre o valor do salário mínimo e a sua política de valorização de longo prazo. Diário Oficial da União [Internet] 2011 [acesso em 26 mar 2013]. Disponível: http://www.normaslegais.com. $\mathrm{br} /$ legislacao/decreto-7655-2011.htm.

24. Ferreira MR. Empreendedorismo em enfermagem: estratégias de supervisão na formação Inicial [dissertação]. Aveiro (Portugal): Universidade de Aveiro; 2010.

25. Regis LFLV, Porto IS. Necessidades humanas básicas dos profissionais de enfermagem: situações de (in) satisfação no trabalho. Rev Esc Enferm USP. [Internet] 2011;45(2) [acesso em 29 mar 2013]. Disponível: http:// dx.doi.org/10.1590/S0080-62342011000200005

26. Rangel RF, Fugali MM, Backes DS, Gehlen MH, Souza MHT. Avanços e perspectivas da atuação do enfermeiro em Estratégia Saúde da Família[editorial].Cogitare enferm. 2011;16(3):498-504. 